\title{
Development of Attrition Resistant Iron-Based Fischer-Tropsch Catalysts
}

Type of Report:

Reporting Period:

Project Manager:

Date:

DOE Award Number:

Name and Address:

DOE Project Officer:
Technical Progress Report, Report Number: 1

September 1, 1999 - August 31, 2000

Adeyinka A. Adeyiga

September 20, 2000

DE-FG26-99FT40619--01

Hampton University

Department of Chemical Engineering

Hampton, VA 23668

Dr. Udaya Rao 


\section{DISCLAIMER}

This report was prepared as an account of work sponsored by an agency of the United States Government. Neither the United States Government nor any agency thereof, nor any of their employees, makes any warranty, express or implied, or assumes any legal liability or responsibility for the accuracy, completeness, or usefulness of any information, apparatus, product, or process disclosed, or represents that its use would not infringe privately owned rights. Reference herein to any specific commercial product, process, or service by trade name, trademark, manufacturer, or otherwise does not necessarily constitute or imply its endorsement, recommendation, or favoring by the United States Government or any agency thereof. The views and opinions of authors expresses herein do not necessarily state or reflect those of the United States Government or any agency thereof. 


\begin{abstract}
The Fischer-Tropsch (F-T) reaction provides a way of converting coal-derived synthesis gas $\left(\mathrm{CO}+\mathrm{H}_{2}\right)$ to liquid fuels. Since the reaction is highly exothermic, one of the major problems in control of the reaction is heat removal. Recent work has shown that the use of slurry bubble column reactors (SBCRs) can largely solve this problem. The use of iron-based catalysts is attractive not only due to their low cost and ready availability, but also due to their high water-gas shift activity which makes it possible to use these catalysts with low $\mathrm{H}_{2} / \mathrm{CO}$ ratios. However, a serious problem with use of $\mathrm{Fe}$ catalysts in a SBCR is their tendency to undergo attrition. This can cause fouling/plugging of downstream filters and equipment, makes the separation of catalyst from the oil/wax product very difficult if not impossible, and results a steady loss of catalyst from the reactor.
\end{abstract}

Recently, fundamental understanding of physical attrition is being addressed by incorporating suitable binders into the catalyst recipe. This has resulted in the preparation of a spray dried Fe-based catalyst having aps of $70 \mu \mathrm{m}$ with high attrition resistance. This Fe-based attrition resistant, active and selective catalyst gave $95 \% \mathrm{CO}$ conversion through 125 hours of testing in a fixed-bed at $270^{\circ} \mathrm{C}, 1.48 \mathrm{MPa}, \mathrm{H}_{2} / \mathrm{CO}=0.67$ and $2.0 \mathrm{NL} / \mathrm{g}$-cat/h with $\mathrm{C}_{5}{ }^{+}$selectivity of $>78 \%$ and methane selectivity of less than $5 \%$. However, further development of the catalyst is needed to address the chemical attrition due to phase changes that any Fe-catalyst goes through potentially causing internal stresses within the particle and resulting in weakening, spalling or cracking.

The objective of this research is to develop robust iron-based Fischer-Tropsch catalysts that have suitable activity, selectivity and stability to be used in the slurry bubble column reactor. Specifically we aim to develop to: (i) improve the performance and preparation procedure of the high activity, high attrition resistant, high alpha ironbased catalysts synthesized at Hampton University (ii) seek improvements in the catalyst performance through variations in process conditions, pretreatment procedures and/or modifications in catalyst preparation steps and (iii) investigate the performance in a slurry reactor.

The effort during the reporting period has been devoted to effects of pretreating procedures, using $\mathrm{H}_{2}, \mathrm{CO}$ and syngas $\left(\mathrm{H}_{2} / \mathrm{CO}=0.67\right)$ as reductants, on the performance (activity, selectivity and stability with time) of a precipitated iron catalyst $\left(100 \mathrm{Fe} / 5 \mathrm{Cu} / 4.2 \mathrm{~K} / 10 \mathrm{SiO}_{2}\right.$ on a mass basis ) during F-T synthesis were studied in a fixedbed reactor. 
TABLE OF CONTENTS

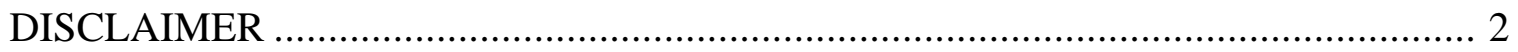

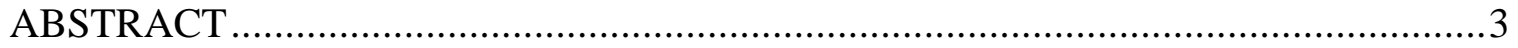

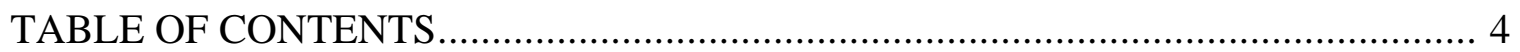

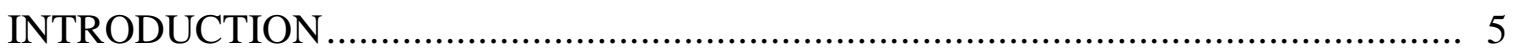

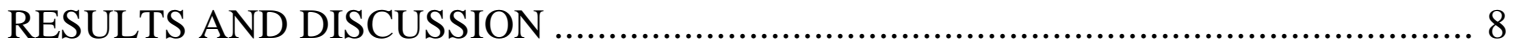




\section{Development of Attrition Resistant Iron-Based Fischer-Tropsch Catalysts}

\section{Introduction}

Fischer-Tropsch Synthesis (FTS) is the reaction of $\mathrm{CO}$ and $\mathrm{H}_{2}$ (syngas) to form a wide variety of hydrocarbons, typically using iron- or cobalt-based catalysts. Currently there are two commercial FTS plants: SASTECH produces synthetic fuels and chemicals from coal (including recent expansions), and Shell is using FTS to convert natural gas to high value products in Malaysia. There are other units in the planning or construction stage: China plans to make town gas via FTS; Williams Company is constructing a pilot plant to determine the economics of underground coal gasification; and Exxon is evaluating the possibility of locating a large natural gas-based FTS plant in Quatar. These activities clearly show that improvements and innovations in FTS are underway. This process is also strategically important to the U.S. because of its vast coal reserves, and because FTS represents the best means to make high quality transportation fuels and liquid products from coal. In addition to other technical challenges, one of the major problems in control of the reaction is heat removal. Recent progress in this area has focused on the use of a slurry bubble column reactor (SBCR). These reactors offer simple designs and low costs while still permitting high catalyst and reactor productivity. It is generally thought that this will be the reactor of choice for commercial, coal-based FTS in the United States.

Since modern coal gasification plants produce a syngas that is relatively lean in $\mathrm{H}_{2}\left(\mathrm{H}_{2} / \mathrm{CO}=0.5-0.7\right)$, a catalyst which is active for the FTS reaction $\left(\mathrm{CO}+2 \mathrm{H}_{2} \rightarrow-\right.$ $\left.\mathrm{CH}_{2^{-}}+\mathrm{H}_{2} \mathrm{O}\right)$ and the water-gas shift (WGS) reaction $\left(\mathrm{CO}+\mathrm{H}_{2} \mathrm{O} \rightarrow \mathrm{CO}_{2}+\mathrm{H}_{2}\right)$ is required. The overall reaction on these catalysts is thus $2 \mathrm{CO}+\mathrm{H}_{2} \rightarrow-\mathrm{CH}_{2^{-}}+\mathrm{CO}_{2}$. This allows the efficient use of low $\mathrm{H}_{2} / \mathrm{CO}$ syn gas. Iron-based catalysts, which are active shift catalysts, are thus preferred over cobalt-based catalysts, which are not. Iron is also much less expensive than cobalt. 
F-T products are very desirable from an environmental point of view. Because F$\mathrm{T}$ catalysts are very sulfur sensitive, the feed must be completely sulfur free which means that the product is also sulfur free. In addition to being sulfur free, the product is also nitrogen and aromatics free. F-T diesel fuel has a very high cetane number. Although raw F-T naphtha has a low octane number, it can be processes into high quality gasoline. F-T distillate also makes excellent ethylene plant feedstock.

Catalyst development activities have involved an extensive effort to improve the performance of iron catalysts. Iron catalyst development work has been carried out by the Center for Advanced Energy Research (CAER) and FETC's Office of Science and Technology (OST). These efforts have resulted in iron catalysts with much higher activities than previous catalysts. A problem with iron catalysts is that they tend to have low structural strength with the result that attrition tends to produce very small catalyst particles during slurry operations. This attrition causes plugging, fouling, difficulty in separating the catalyst from the wax product, and loss of the catalyst. This is due to the low attrition resistance of the Fe catalyst and the significant breakage of the Fe particles. Fe catalysts are subject to both chemical as well as physical attrition in a SBCR. Chemical attrition can be caused due to phase changes that any Fe catalyst goes through $\left(\mathrm{Fe}_{2} \mathrm{O}_{3} \rightarrow \mathrm{Fe}_{3} \mathrm{O}_{4} \rightarrow \mathrm{FeO} \rightarrow \mathrm{Fe} \rightarrow \mathrm{Fe}\right.$ carbides) potentially causing internal stresses within the particle and resulting in weakening, spalling or cracking. Physical attrition can result due to collisions between catalyst particles and with reactor wall. Catalyst particles of irregular shapes and non-uniform sizes produced by conventional methods are subject to greater physical attrition.

Another inherent complication associated with the iron-based catalyst is the catalyst pretreatment. Before synthesis, a catalyst precursor is pretreated to convert the catalyst into an active form. The pretreatment of $\mathrm{Fe}$ is not as straight forward as that for $\mathrm{Ru}, \mathrm{Co}$ or Ni. Although pretreatment includes reduction of the iron particles, other processes are also involved. The pretreatment of iron FT catalysts is not clearly 
understood. Part of the confusion stems from the fact that the nature and composition of iron catalysts change during reaction. These changes depend on the temperature, time of exposure to the reactant feed, nature of the reactor system, and composition of the feed, and activation conditions (time and temperature). The common pretreatment conditions employed in the case of iron catalysts are $\mathrm{H}_{2}$ reduction, $\mathrm{CO}$ reduction (and carbiding), or reduction in the reactant syngas. Work at the Federal Energy Technology Center has focused on the effect of catalyst pretreatment and the impact of the liquid starting medium on syngas conversion in a stirred tank slurry reactor.

Several phases of iron are known to exist when iron-based catalysts are subjected to F-T synthesis conditions. These include metallic iron $(\alpha-\mathrm{Fe})$, iron oxides (hematite, $\alpha-\mathrm{Fe}_{2} \mathrm{O}_{3}$; magnetite, $\mathrm{Fe}_{3} \mathrm{O}_{4}$ and $\mathrm{Fe}_{\mathrm{x}} \mathrm{O}$ ), and iron carbides, of which at least five different forms are known to exist. These include O-carbides (carbides with carbon atoms in octahedral interstices, $\varepsilon-\mathrm{Fe}_{2} \mathrm{C}, \varepsilon^{\prime}-\mathrm{Fe}_{2.2} \mathrm{C}$, and $\mathrm{Fe}_{\mathrm{x}} \mathrm{C}$ ) and TP-carbides (carbides with carbon atoms in trigonal prismatic interstices, $\chi-\mathrm{Fe}_{2.5} \mathrm{C}$ and $\mathrm{Fe}_{3} \mathrm{C}$ ). The formation and distribution of these phases depend on the reaction conditions, reaction times, and state of the catalyst (reduced/unreduced, supported/unsupported, etc.). However, the role of each of these phases during the reaction has not been resolved.

Potassium and copper are typically used as chemical promoters for iron FT catalysts. The adsorption of $\mathrm{CO}$ on iron results is a net withdrawal of electrons from the metal, whereas hydrogen adsorption tends to donate electrons to the metal. Potassium and the associated $\mathrm{O}^{2-}$ donate electrons to the metal, enhancing $\mathrm{CO}$ adsorption while weakening $\mathrm{H}_{2}$ adsorption. This leads to decreased hydrogenation and increased chain growth during the synthesis reaction, yielding higher molecular weight products (i.e., a higher $\alpha$ ). More lower olefins are also produced. Potassium also decreases $\mathrm{CH}_{4}$ production and increases WGS activity. Copper on the other hand is introduced to facilitate reduction of the iron itself. Copper is more effective in increasing the FTS 
reaction rate than potassium. Also the average molecular weight is increased in the presence of copper.

The objective of this research is to develop robust iron-based Fischer-Tropsch catalysts that have suitable activity, selectivity and stability to be used in the slurry bubble column reactor. Specifically we aim to develop to: (i) improve the performance and preparation procedure of the high activity, high attrition resistant, high alpha ironbased catalysts synthesized at Hampton University (ii) seek improvements in the catalyst performance through variations in process conditions, pretreatment procedures and/or modifications in catalyst preparation steps and (iii) investigate the performance in a slurry reactor.

\section{RESULTS AND DISCUSSIONS}

The project consists of four experimental tasks (Tasks 1-4) addressing the contract objectives described above:

Task 1:Catalyst Preparation

Task 2:Catalyst Performance Evaluation

Task 3:Catalyst Characterization

Task 4:Slurry Reactor Testing

\section{Task 1: Catalyst Preparation}

Attrition resistant Fe-based catalysts $\left(100 \mathrm{Fe} / 5 \mathrm{Cu} / 4.2 \mathrm{~K} / 10 \mathrm{SiO}_{2}\right.$ on a mass basis) was prepared using precipitation methods. The resultant catalyst precursor was spray dried to produce micro-spheroidal particles $(>50 \mu \mathrm{m})$ followed by air-calcination at $300^{\circ} \mathrm{C}$ to produce attrition-resistant spheroidal catalysts.

\section{Task 2. Catalyst Performance Evaluation}

Fixed-bed F-T testing was used to determine the catalyst performance characteristics. The catalyst was activated in flowing $\mathrm{H}_{2}, \mathrm{CO}$, and a $\mathrm{H}_{2} / \mathrm{CO}=0.7 / 1.0$ mixture at the temperature of $280^{\circ} \mathrm{C}$. After activation, reactions were carried out over the 
catalyst samples in the reactor tube at $270^{\circ} \mathrm{C}, 1.48 \mathrm{MPa}, \mathrm{H}_{2} / \mathrm{CO}=0.67$, and $2.0 \mathrm{NL} / \mathrm{g}$ cat/h.

Variation of synthesis gas conversion with time on stream after three different pretreatments are shown in Figure 1. The activity of the syngas $\left(\mathrm{H}_{2} / \mathrm{CO}=0.67\right)$ pretreated catalysts was the highest among all the pretreatment procedure used. At steady state, the $\mathrm{CO}$ conversion is greater than $80 \%$ for both $\mathrm{CO}$ and syngas pretreatment catalysts. However, the $\mathrm{CO}$ conversion is about $45 \%$ for $\mathrm{H}_{2}$ pretreatment catalysts. There was no significant change with time in $\mathrm{CO}$ conversion or hydrocarbon selectivities over the test duration, typically 200 to $350 \mathrm{~h}$. The alpha value for all three pretreatments tested range from 0.87 to 0.91 .

Attrition resistance experiments to determine the effect of pretreatment (in $\mathrm{H}_{2}$, $\mathrm{CO}, \mathrm{H}_{2} / \mathrm{CO}=0.7 / 1.0$ mixture ) on attrition was carried out in a jet cup. The attrition resistance results for all three different pretreatment procedure are shown in Table 1.

Table 1. Jet cup attrition resistance test results

\begin{tabular}{|l|l|}
\hline Catalysts & Attrition, wt \% \\
\hline Fresh (calcined) & 4.8 \\
\hline CO pretreated & 3.06 \\
\hline $\mathrm{H}_{2} / \mathrm{CO}$ pretreated & 3.85 \\
\hline $\mathrm{H}_{2}$ pretreated & 4.02 \\
\hline
\end{tabular}

The attrition was found less compare to the attrition of the same catalyst under calcined state.

\section{Task 3. Catalyst Characterization}

This task provides support to each of the previous tasks. The following analytical techniques are used to characterize the fresh, pretreated and used catalysts. 1) Total 
surface area measurement using BET method. 2) Hg-porosimetry for pore volume and pore size distributions. 3) X-ray Diffraction (XRD) for the bulk phases of the catalysts. 4) $\mathrm{CO}$ chemisorption on the reduced iron catalysts to measure the available active $\mathrm{Fe}$ surface area. 5) The reducibility of the catalysts by TPR 6) Elemental analysis using atomic absorption (AA) spectrometry.

\section{Task 4. Slurry Reactor Testing}

New CSTR was purchased. Currently, we are in the process of installing the

CSTR reactor.

\section{FUTURE WORK}

Work will continue to develop robust iron-based F-T catalysts that have suitable activity, selectivity and stability to be used in the slurry bubble column reactor. 


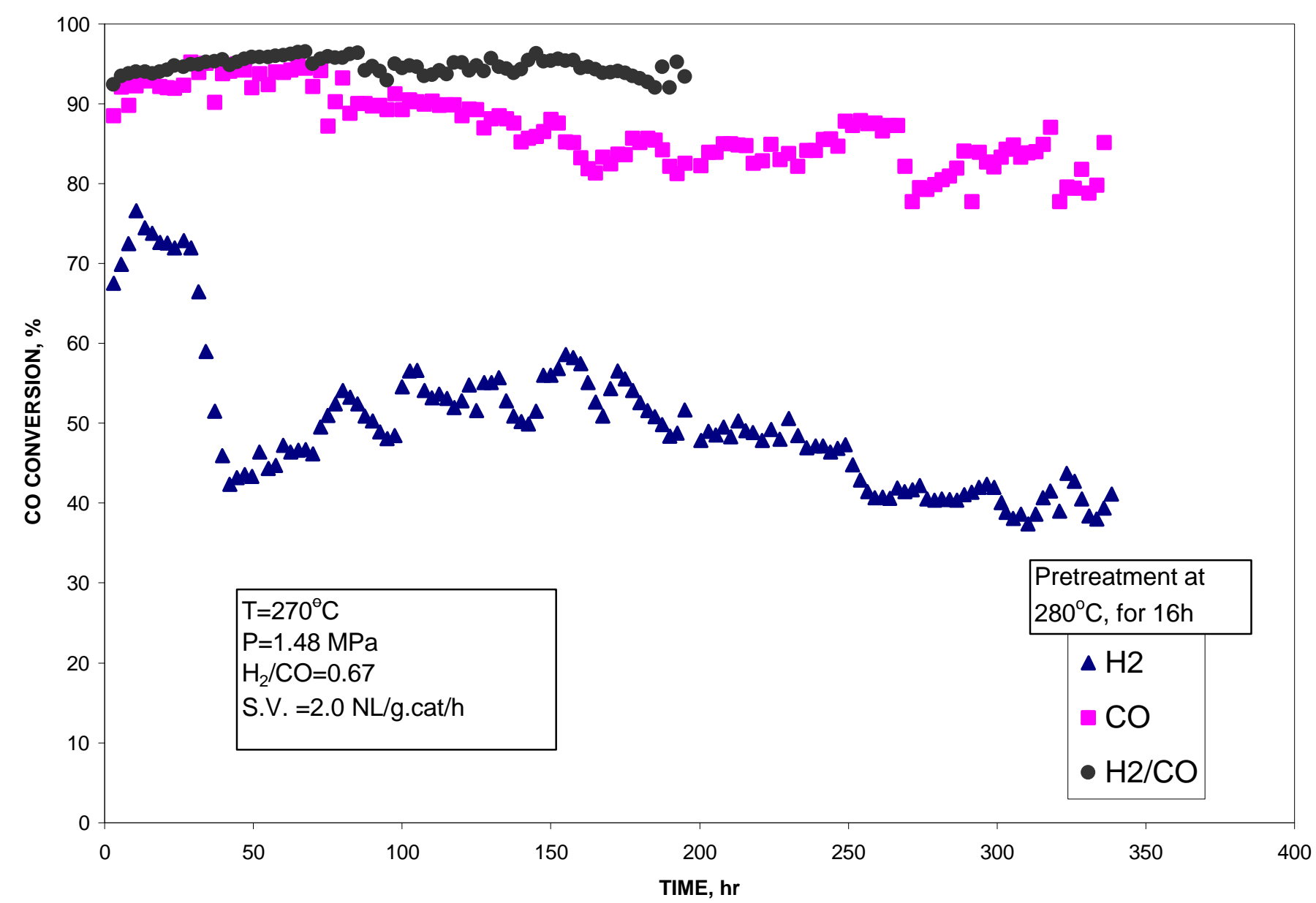

Figure 1. Variation of synthesis gas conversion with time on stream after different pretreatments 